\title{
Estímulos e apoio às atividades empresariais
}

\author{
EntreVISTA de SÉrgio PASSARINHo e I SABEL Marinho
}

$\mathrm{N}$ A BAH IA, a luta contra as desigualdades raciais vem trilhando caminhos inéditos. $U$ m deles é o apoio governamental a empreendimentos na comunidade dos afro-descendentes. Com esse objetivo, a prefeitura de Salvador iniciou um trabalho conjunto e articulado da Secretaria Extraordinária de D esenvolvimento E conômico com a Secretaria M unicipal da Reparação. $\mathrm{N}$ a execução dessa política, entre outras iniciativas, foi criada uma G erência de E conomia Cultural, a fim de explorar a possibilidade de negócios dos afro-descendentes.

Para obter mais informações a respeito dessas atividades, ESTU D OS A VA N ÇA D OS realizou entrevistas na prefeitura de Salvador com Sérgio Passarinho, chefe da Secretaria Extraordinária do D esenvolvimento Econômico, e com a economista I sabel M arinho, responsável pela Gerência de E conomia Cultural.

\section{O trabalho conjunto com a Secretaria da R eparação}

EStudos Avançados - Qual o relacionamento do trabalho da Secretaria Extraordinária do D esenvolvimento E conômico com a Secretaria M unicipal da Reparação? Como o desenvolvimento econômico pode contribuir para ser eliminada a discriminação racial?

Sérgi o Passari nho- Partimos do princípio de que tudo o que for realizado para a população pobre beneficiará os afro-descendentes em Salvador. Sendo assim, um dos objetivos da Secretaria, da qual sou responsável, é contribuir para o desenvolvimento da capacidade empresarial dos afro-descendentes. Por isso, criamos a G erência de E conomia C ultural, pensando que, dentro das perspectivas de geração de renda e de emprego para a população de Salvador, seria interessante nos envolvermos com a produção de bens e serviços indispensáveis aos eventos culturais. Todavia, não nos preocupamos diretamente com a promoção do carnaval em Salvador. 0 que nos cabe fazer é acompanhar a produção daquilo que é usado no carnaval. Por exemplo, saber como e onde são fabricados os abadás e as camisetas usadas e vendidas pelas organizações populares.

Essa G erência foi criada um ano e meio atrás e a partir de então começamos a estudar as possibilidades de desenvolvimento econômico nas áreas da cultura. V isitamos blocos afros e apuramos que grande parte de sua indumentária ainda é produzida fora do Estado, como os trinta mil colares que anualmente vinham de São Paulo. H oje os blocos montam esses colares, mas ainda compram as miçangas 
em São Paulo. Constatamos então que em todas atividades culturais em Salvador são consumidos bens e serviços produzidos em outros lugares que não em nossa cidade. O utro exemplo: as fitinhas do Senhor do Bonfim, parte da estatuária do candomblé, assim como os brindes do "Olodum" e do "Ilê Ayê" não são fabricados na B ahia. Temos, então, de analisar se é possível economicamente trazer a produção de uma parte desses bens para Salvador. Em conseqüência, começam a aparecer alguns dados positivos, como o interesse de uma empresa que vai montar aqui um núcleo de alta tecnologia para fazer o que chamam de cd master, a partir do qual são reproduzidos milhares de CDS.

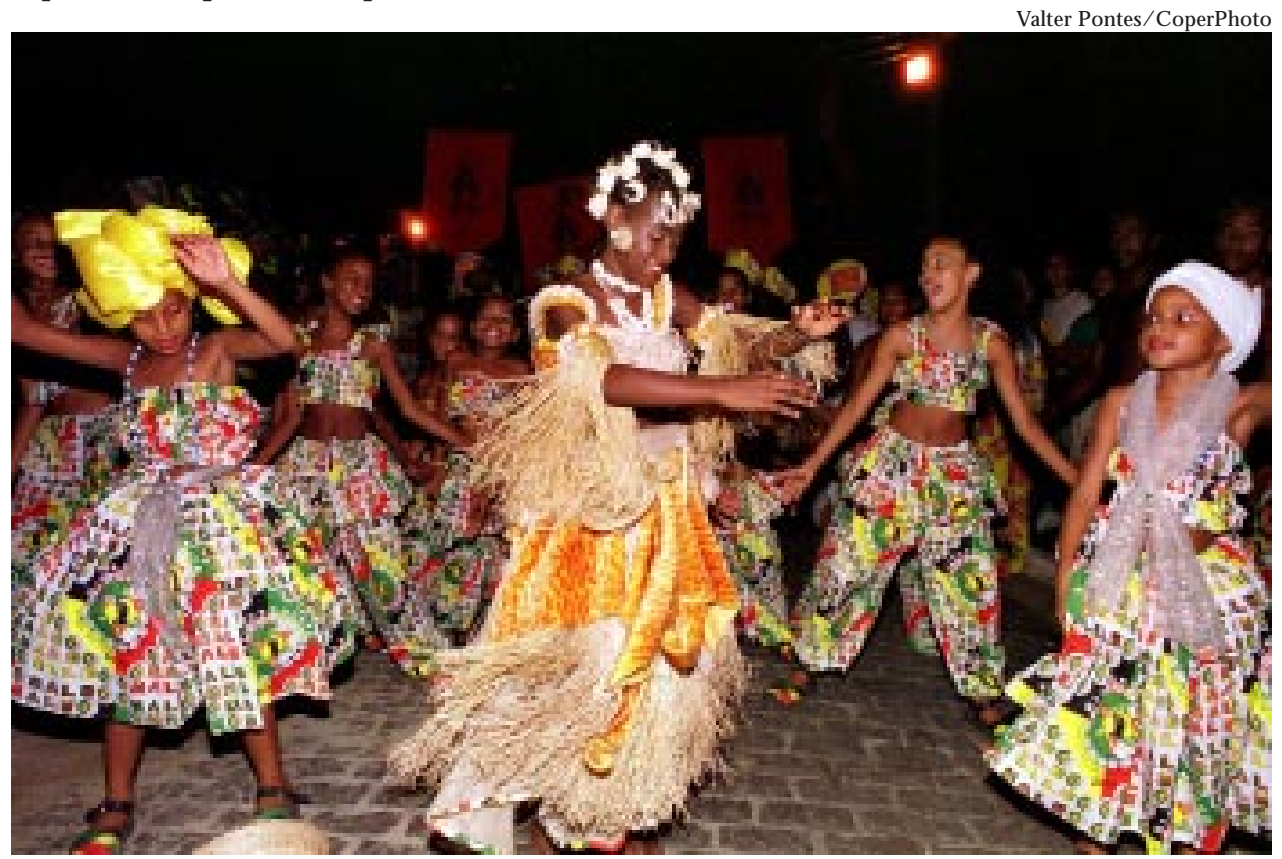

Este ano o bloco "A fro I lêA yê", considerado o mai sfamoso da capital baiana, completa 30 anos.

O professor Noélio Spínola coordenou um estudo sobre a economia da cultura na Bahia. Verificou, então, que os afro-descendentes, principalmente, se acostumaram a viver com poucas coisas, de modo bastante precário. Por isso tentamos convencê-los de que podem fazer empreendimentos que lhes assegurar um padrão de vida melhor.

E sse discurso tem sido bem aceito em todos contatos que realizamos. U m empresário da construção civil, por exemplo, com mais de vinte anos de atuação nessa área, disse-me que estava cansado do palavreado teórico contra a discriminação racial, e que poderemos efetivamente avançar se houver apoio e estímulo às atividades econômicas desenvolvidas pelas comunidades negras.

Acreditamos, portanto, que, ao impulsionar a capacidade dos afro-descendentes, estaremos contribuindo para a superação da desigualdade racial, pelo menos em Salvador. Aqui, ninguém faz abertamente proclamações discrimina- 
tórias. E se fizer vai preso. $\mathrm{N}$ ão existe mais, portanto, uma discriminação racial aberta e formal. M as esta só diminui na medida em que ocorre a ascensão social e econômica dos afro-descendentes. Com essa visão, nossa equipe está desenvolvendo esforços no sentido de convencer a população negra da necessidade do treinamento para se aprender a gerenciar os empreendimentos.

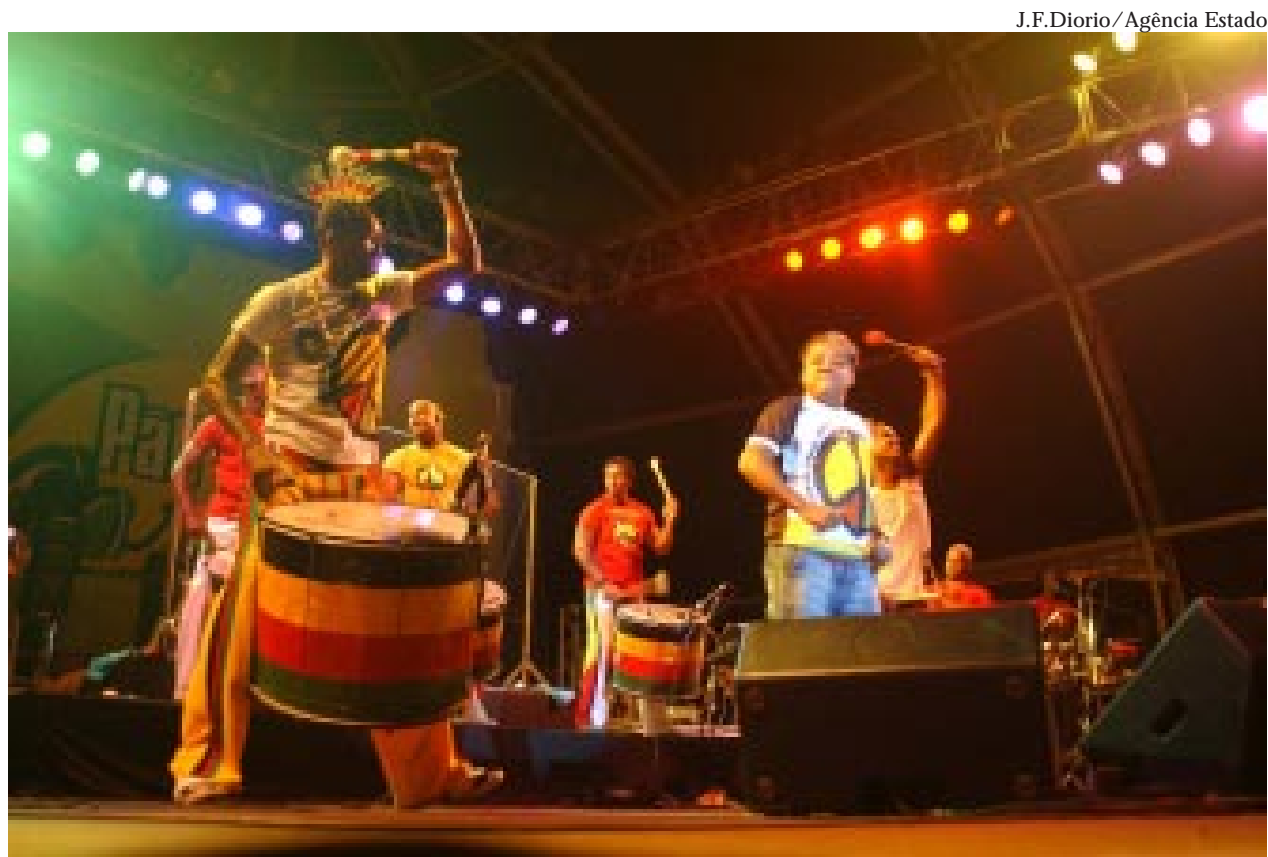

Show do Grupo Olodum realizado em novembro de 2003, na Praça da Paz, no I bi rapuera, SP.

\section{U ma experiência na área de serviços}

E STU D os A VA N çA D os - Secretário, como foi a negociação com uma empresa de call center que beneficiou a população afro-descendente?

Sérgi o Pasarinho- É impressionante o crescimento, no Brasil eno mundo, desses call centers. Eles realizam 0 atendimento por telefone, utilizando uma massa enorme de empregados que dão e recebem informações para diversas empresas. Como funcionam 24 horas por dia, em vários turnos de trabalho, um posto pode corresponder a três ou quatro empregos. Basta se pensar no uso fantástico de dezenas de milhões de cartões, emitidos pelos bancos e empresas comerciais. E tudo indica que cada vez mais esses call centersserão indispensáveis e necessitam expandir a contratação de mão-de-obra qualificada.

$\mathrm{H}$ á um ano e meio fizemos um acordo com uma dessas empresas. Conseguimos encontrar um caminho legal para que sua sede não fosse transferida da B ahia. $\mathrm{N}$ egociamos então a contratação de afro-descendentes. $\mathrm{M}$ as, de que forma? $\mathrm{C}$ omo ela empregava estudantes universitários, a prefeitura resolveu Ihe conceder incentivos fiscais, desde que passasse a fazer a contratação de empregados nas escolas públicas de segundo grau, porque neles, em sua maioria, os estudantes são afro- 
descendentes. A empresa aceitou e o resultado foi a abertura de vagas para muitos estudantes negros e mestiços.

\section{0 relacionamento com os norte-americanos}

ESTU D os A VAN ÇAD os - Como estão evoluindo os contatos com empresários norte-americanos negros tendo em vista seu apoio às atividades econômicas de afro-descendentes no Bahia?

Sérgio Passarinho - Dois anos atrás discutimos essa questão com o empresário norte-americano Weldon Rougeau, presidente da Fundação Blackcaucus. Ele nos explicou que sua instituição surgiu, na década de 1960, com 0 objetivo realizar diversas ações em defesa dos interesses e dos direitos da comunidade de afro-descendentes nos E stadosU nidos. (N esse país os afro-descendentes são cinqüenta e cinco milhões, sendo que o PIB deles é maior que o PIB brasileiro.)

Recentemente, a Fundação Blackcaucus decidiu impulsionar o relacionamento comercial e financeiro com as comunidades de afro-descendentes de outros países, entre os quais o Brasil. D aí o seu interesse em verificar na Bahia a possibilidade de algumas transações, entre as quais uma parceria na área de turismo.

Em conseqüência, portanto, trabal hamos para incluir a Bahia nesse roteiro da Blackcaucus, dentro de um projeto do governo do Estado, no qual a nossa prefeitura participa, tendo em vista a criação de um grande projeto de entretenimento com o objetivo de incrementar a vinda a Salvador de turistas norteamericanos.

Essa negociação chegou numa boa hora porque sentimos que, apesar de estar crescendo o número de turistas, há um empobrecimento relativo do turista médio. Assim, estamos articulando os vários setores do segmento turístico para ampliar o turismo de afro-descendentes norte-americanos na Bahia.

Ao lado disso, começamosa realizar encontros internacionais que objetivam promoção de programas de desenvolvimento sustentável, voltados para o apoio mútuo das comunidades de afro-descendentes nas A méricas.

\section{N egócios culturais}

Estud os A VANÇAD os - I sabel M arinho, a sra. atualmente é a gerente do setor de Economia Cultural, na Secretaria Extraordinária de D esenvolvimento E conômico. Acredita que há condições para o desenvolvimento dessas atividades em Salvador? Elas podem gerar empregos e ajudar a população negra?

I sabel Marinho - A criação dessa gerência foi muito recente e, quando fui convidada a assumir sua direção, voltei para a universidade para fazer uma especialização em economia. Como empresária, acredito que poderemos auxiliar os empreendimentos econômicos dos afro-descendentes, porque minha experiência indica que as pessoas que investem em cultura podem ganhar dinheiro. Além disso, a prefeitura dá apoio a essas iniciativas. 
ESTU D os A VAN ÇAD os - A sra. é administradora de empresas, em que ramos atua sua empresa?

I sabel Marinho - Depois de fazer o magistério, estudei artes cênicas na UFBa, porque isso me facilitaria conseguir um emprego. Q uando fiz dezessete anos, meus pais me emanciparam e abri uma empresa que existe até hoje. É uma empresa de eventos: primeiro, trabal hei fazendo animação de festas de aniversário; depois procurei me inserir num novo campo, trabalhando para empresas de médio e grande porte que investem na sociabilização dos funcionários, a fim de elevar sua produtividade. Fundei grupos de teatro no D etran, na Bahiatur, na I mbasa, no Centro de Recursos Ambientais etc. Agora estou envolvida com a área da saúde e trabal ho usando as ferramentas da arte e da cultura para a educação de comunidades carentes.

\section{A história de uma empresária negra}

ESTUd os A van çA D os - I sabel, conte um pouco sua vida. Como foi sua carreira para se tornar uma empresária vitoriosa e ocupar um cargo destacado na prefeitura de Salvador?

I sabel Marinho- M inha família trabalhava numa fazenda, meu pai tomava conta do gado e minha mãe, desde pequena, trabalhava dentro da casa. Ela nunca ganhou salário e nunca teve carteira assinada. Era uma escrava. Precisava trabal har ali para que pudéssemos morar na terra. Depois que os filhos se tornaram adolescentes, fugimos de lá porque os donos da terra não queriam que saíssemos da propriedade.

M eus pais, analfabetos, vieram para Salvador e fomos morar num quartinho de vila (quartinhos com um único banheiro para várias famílias). M eu pai era ajudante de pedreiro e minha mãe foi lavar roupa para fora.

Sempre estudei em escola pública. D epois de me formar como professora fui estudar numa universidade pública. Fiz duas especializações e estou agora me preparando para o mestrado. M inha ascensão financeira e profissional foi galgada degrau por degrau, muito lentamente. $\mathrm{H}$ oje administro duas empresas e sou presidente de uma ONG. 